\title{
Piriformis syndrome: Pathogenesis, diagnosis, and treatment
}

\author{
CHARLES STEINER, D.O., FAAO \\ Maplewood, New Jersey \\ CHARLES STAUBS, B.S. \\ Lindenwold, New Jersey \\ MICHAEL GANON, D.O. \\ Littleton, Colorado \\ CHRISTINE BUHLINGER, D.O. \\ Morrison, New Jersey
}

The failure of conservative treatment for lumbosacral disk disorders often leads to surgery. If the pain is produced by sciatic neuritis rather than sciatic radiculitis, operative treatment may be unavailing. This paper describes the mechanism by which piriformis syndrome causes sciatic neuritis and differentiates neuritis from radiculitis, the treatment of which often results in the "failed disk syndrome." Sciatic neuritis is now believed to result from irritation of the sciatic nerve sheath, which is caused by biochemical agents released from an inflamed piriformis muscle where the two structures meet at the greater sciatic foramen. The symptoms of piriformis syndrome present almost identically to lumbar disk syndrome, except for the consistent absence of true neurologic findings. Diagnosis is accomplished by palpation of myofascial trigger points within the piriformis muscle. Computed tomography, myelography, roentgenography, and electromyography are of limited diagnostic value. Treatment, which consists of a conservative approach employing local anesthetics and osteopathic manipulation, is without significant risk. Reducing muscle spasm, restoring joint motion, and keeping the patient ambulatory and in motion are keys to successful treatment.
Persistent or severe pain along the distribution of the sciatic nerve may be produced by irritation or mechanical trauma anywhere along its course. Two common causes of sciatic distribution pain are lumbar disk herniation and piriformis syndrome..$^{1-3}$ Back pain is common to both. It has been our experience that direct conservative measures may be employed effectively in both differential diagnosis and treatment of herniated lumbar disk and piriformis syndrome. The ambulatory conservative treatment of disk disease has been described previously. ${ }^{4}$ Our aim in this paper is to provide an understanding of the different symptomatology of and a therapeutic approach to the piriformis syndrome.

\section{Microanatomy of the sciatic nerve}

The sciatic nerve, a "typical" peripheral nerve, is ensheathed by epi-, peri-, and endo-neurium. The epineurium surrounds the whole nerve, the perineurium surrounds individual nerve fascicles, and the endoneurium surrounds individual neurons. Below the level of the endoneurium, myelinated fibers are encompassed by Schwann's cells and myelin sheaths; unmyelinated fibers lack the latter. ${ }^{5}$

The function of the connective tissue sheaths sur- 
rounding the sciatic nerve is to provide protection against mechanical and chemical insult. The epineurium and perineurium provide mechanical protection; the perineurium also serves as a chemical diffusion barrier because of the absence of pinocytotic transport and the presence of occluding junctions that connect its epithelioid cells. ${ }^{5-7}$ The diffusion barrier of perineurium combined with the blood-nerve barrier of the endoneurial vessels provide the sciatic nerve with an environment isolated from chemical conditions outside its barriers. ${ }^{7}$ Only in cases of crushing trauma or severe ischemia are these barriers breached. ${ }^{7,8}$

The connective tissue sheaths that surround the nerve roots and sciatic nerve are innervated by nerve fibers called the nervi nervorum. The ventral nerve root connective tissue sheath receives fibers from the sinu-vertebral nerve, and the dorsal nerve root connective tissue sheath receives fibers from spinal ganglia. ${ }^{9}$ The sciatic nerve connective tissue sheath receives fibers from the plexuses of nutrient arteries and nerve fascicles of the sciatic nerve. ${ }^{10}$ Many of the nervi nervorum fibers are unmyelinated, with free nerve endings indicative of type C nociceptive neurons. Histamine and bradykinin applied to nociceptive free nerve endings result in pain, while prostaglandin $\mathrm{E}$ applied to nociceptors produces hyperalgesia to mechanical and histamine stimuli. ${ }^{11}$

Because both the root sheath and peripheral nerve sheath derive their innervation from the spinal nerve roots that form the sciatic nerve, irritation of either will result in pain perceived as being along the somatotopic distribution of the sciatic nerve. This is due to convergence of visceral, muscular, and cutaneous pain fibers on dorsal horn cells in Rexed's lamina 5 of the spinal cord, which prevents the body from clearly differentiating visceral and cutaneous pain. ${ }^{11,12}$ The tendency is to refer visceral and subcutaneous pain to the cutaneous somatotopic map in the brain. Therefore, sciatica can result from irritation of the sciatic nerve sheath either at the roots or anywhere along the course of the peripheral nerve because of the nervi nervorum nociceptors located within the sheath.

\section{Gross anatomy of the sciatic nerve and piriformis muscle}

The sciatic nerve, rather than a single trunk, consists of the peroneal and tibial portions, which are, in most cases, bound together by the fibrous epineurium as the nerve runs distally to the popliteal space. The peroneal portion usually is derived from fibers of the fourth and fifth lumbar and first and second sacral spinal nerves. The tibial division has additional fibers from the third sacral spinal nerve.
The two parts of the nerve within their common sheath usually pass between the piriformis muscle above and gemelli muscles below. It travels through the buttock and out of the pelvis through the greater sciatic foramen. The nerves usually will not pursue separate courses until reaching the popliteal space. ${ }^{13}$

The piriformis muscle typically arises from the anterior surface of the second through the fourth sacral vertebra, the upper margin of the greater sciatic foramen, and the sacrotuberous ligament, to insert on the superior surface of the greater trochanter of the femur (Fig. 1). However, variations exist in a significant percentage of the population. The contraction of the piriformis muscle produces abduction and external rotation of the thigh. Occasionally, the origin is fused with the overlying glutei muscles or underlying superior gemellus muscle. In about 20 percent of the population, the muscle is split and one or both parts of the sciatic nerve pass through the muscle belly. ${ }^{13}$ In 10 percent of the population, the tibial and peroneal portions of the sciatic nerve are not enclosed in a common sheath, and one (usually the peroneal part) or, rarely, both parts may pierce the muscle..$^{13}$

\section{Sciatic neuritis versus sciatic radiculitis}

The processes leading to sciatic radiculitis as opposed to sciatic neuritis are quite different. In the lumbar spine, the integrity of the spinal nerve roots may be influenced by the encroachment of a bulging disk, cord tumor, osteophytes, extravasated blood, spinal stenosis, or pedicular kinking. ${ }^{14}$ Sciatic radiculitis caused by a bulging disk results in unequivocal neurologic signs, including loss of deep tendon reflexes at the patella or ankle (depending on whether the root involved is L3, L4, or $\mathrm{S} 1$, respectively) and paresis of muscles supplied by the involved segment. 3,15 The symptoms may be produced or increased by coughing, sneezing, or straining because they cause an increase in spinal fluid pressure. Such pressure on an already inflamed root may cause pain in the low back and down the leg, paresthesia along the sciatic nerve distribution, and coldness of the foot. These symptoms together with weakness in foot dorsiflexion, foot drop, and flaccidity of the extensor hallucis longus muscle lead to a diagnosis of sciatic radiculitis. ${ }^{3}$

The signs and symptoms of sciatic neuritis, as exemplified by piriformis syndrome, are distinct from those of sciatic radiculitis. By far, the most important criterion in the differentiation of sciatic pain caused by piriformis syndrome is the lack of a true neurologic deficit. ${ }^{1,2}$ Generally, the only reliable positive sign is point tenderness over either end 
of the piriformis muscle itself; this may be found near its origin just lateral to the midsacrum and its insertion just medial to the greater trochanter. The symptoms are often intensified by the palpatory examination. The chief symptoms are pain and/or paresthesia anywhere along the course of the sciatic nerve.

The qualitatively different pathogenesis of these two entities is responsible for the similar but divergent symptomatology. In the disk syndrome, mechanical trauma to the nerve root results in intraneural pathology. ${ }^{16,17}$ Compression or stretching of a nerve root by a bulging disk may result in segmental demyelination, impairment of intraneural blood flow, and intraneural edema and inflammation. ${ }^{16-18}$ Extreme compression may even result in axonal transport block interfering with trophic functions of the axon. ${ }^{17}$ Demyelination, ischemia, and axonal transport block result in deterioration of nerve function, which is observed clinically as neurologic deficits. ${ }^{17}$ Inflammatory agents produced by the mechanical trauma to the nervous tissue and intraneural blood vessels, particularly bradykinin and prostaglandins, may be responsible for the radicular pain. ${ }^{9,19}$ Such chemicals could produce sciatica by irritation of nervi nervorum nociceptors located within the nerve root connective tissue. ${ }^{9-12}$

Reduction of the bulging disk by osteopathic manipulative treatment ${ }^{4}$ removes the source of trauma from the root and results in reversal of the demyelinating, ischemic, and irritative processes, as indicated clinically by improved nerve function and/or reduction of sciatica.

The piriformis syndrome has been attributed to contracture of the muscle resulting in pressure on the sciatic nerve. ${ }^{2}$ Compression of a nerve usually results in impairment or loss of conduction. ${ }^{17,20}$ With the previously mentioned absence of neurologic findings, it is likely that epineurial irritation alone, not compression, is responsible for the pain and paresthesia. This irritation may not be from the muscle spasm itself, but from a complex inflammatory process set into motion by the spasm. Awad $^{21}$ terms the entire process "interstitial myofibrositis." Other authors ${ }^{22,23}$ also have discussed the mechanism by which irritative substances could be released around the nerve. In a series of biopsies of myofascial trigger points, Awad ${ }^{21}$ documented the pathologic findings of metachromatic ground substance (mucopolysaccharide), extravasated platelets, degranulating mast cells, and giant myofilaments. Based on these findings, he hypothesized the probable mechanism of "interstitial myofibrositis" to be as follows: Trauma to the muscle results in extravasation of blood, release of

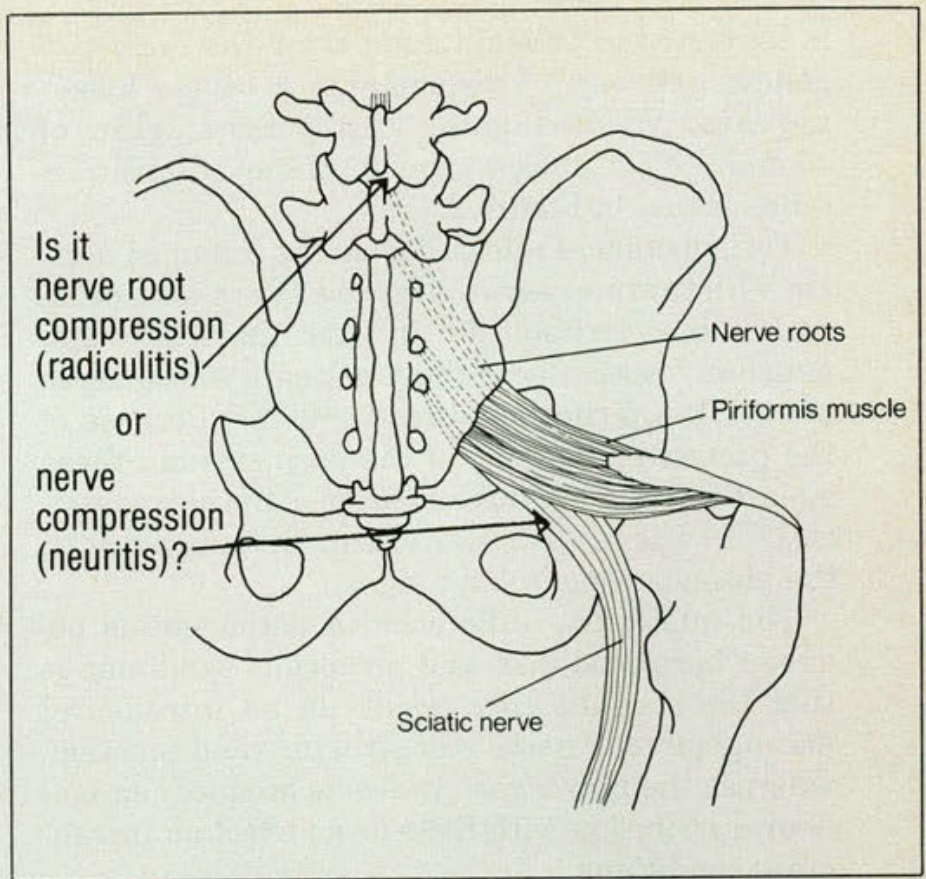

Fig. 1. Nerve irritation in the herniated disk occurs at the root (sciatic radiculitis). In the piriformis syndrome it is to the full thickness of the nerve (sciatic neuritis).

serotonin from extravasated platelets, and degranulation of mast cells releasing histamine and heparin. Serotonin and histamine are vasoactive amines that produce vasodilation and increased vascular permeability. ${ }^{19}$ Heparin inhibits clotting of extravasated blood and lymph. Traumatization may be the result of direct mechanical injury, eccentric contraction, or sudden repeated contraction. ${ }^{21}$ Christensen and Moesmann ${ }^{23}$ believe that muscular hyperfunction (spasm) causes the primary mechanical lesion of the interfibrillar connective tissue.

In addition, we believe that prostaglandin $\mathrm{E}$ and bradykinin may also be generated by trauma to the muscle fibers and blood vessels. Extravasated platelets indicate endothelial damage, and giant myofilaments represent faulty repair of damaged myofibers. ${ }^{21}$ Bradykinin may be generated by damage to endothelium that exposes surface active agents, such as collagen and basement membrane. Contact of plasma Hageman factor with surface active agents activates the plasma kinin generating system, thus resulting in production of bradykinin, an agent that causes pain and increased vascular permeability. ${ }^{11,19}$ Prostaglandin E may be generated by mechanical activation of the phospholipase A2 present in cell membranes. ${ }^{19,24}$ Phospholipase A2 produces arachidonic acid, which 
is converted to prostaglandin $\mathrm{E}$ via the cyclo-oxygenase pathway. ${ }^{19}$ Prostaglandin E causes hyperalgesia, vasodilation, and potentiation of edema. ${ }^{11,19}$ The process of piriformis myofibrositis is schematized in Figure 2.

The substances released from the inflamed muscle-histamine, serotonin, bradykin and prostaglandins-irritate and inflame the sciatic epineurium, especially in those patients whose nerve pierces the piriformis directly. ${ }^{10,11,19,25}$ Because of the protective function of the perineurium, these agents do not cause inflammation of the nerve fascicles. ${ }^{6,7,25}$ The result is sciatic distribution pain with the absence of neurologic signs.

The qualitative difference in pathogenesis between herniated disk and piriformis syndrome is that the disk disorder results in an intraneural derangement of nerve root structure and function, whereas the piriformis syndrome produces an epineural irritation with little or no effect on intraneural conditions.

\section{Differential diagnosis}

Both the disk and piriformis syndromes can produce low-back pain, generalized muscle guarding, limited vertebral mobility, sciatic pain, sciatic paresthesia, and a positive straight leg raising maneu-

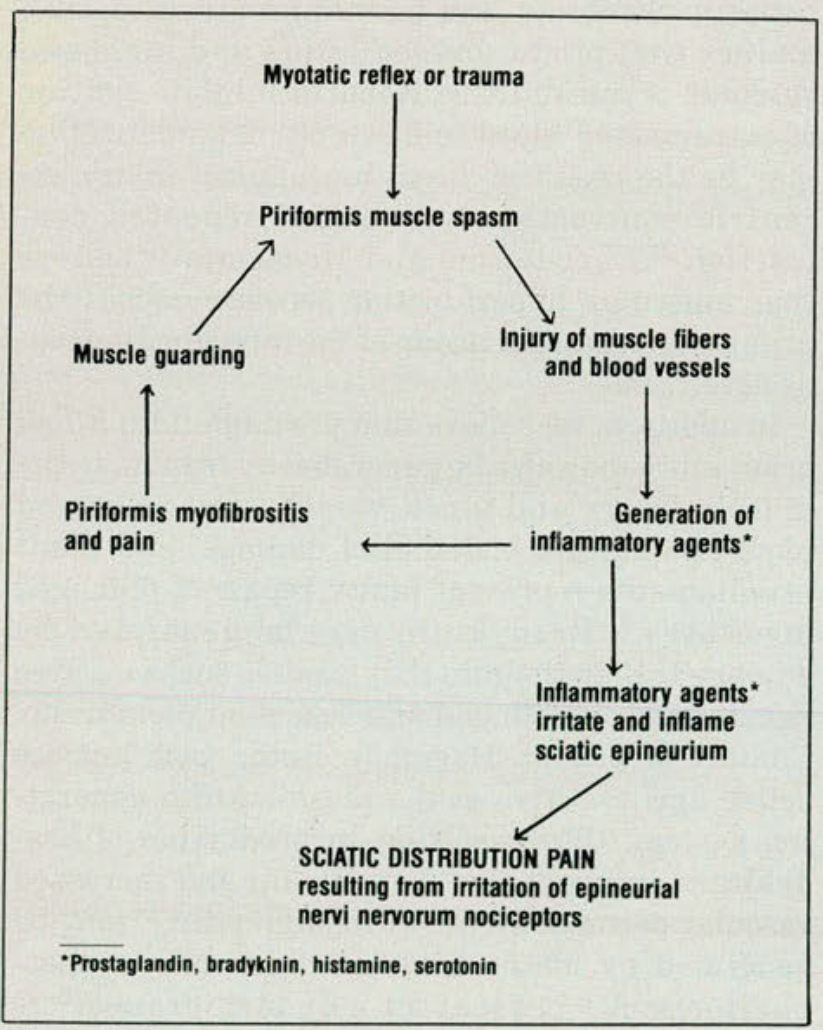

Fig. 2. Piriformis myofibrositis (sciatic neuritis) process. ver. In the herniated intervertebral disk in the lumbar area, there usually is a diminution or loss of deep tendon reflexes in the Achilles or patellar tendons. There may be atrophy of the calf or thigh musculature, weakness of the extensor hallucis longus muscle, and coldness of the affected foot. In piriformis syndrome, there will be increased density over the origin and/or insertion of the piriformis muscle (trigger points). The symptoms usually are intensified by deep palpation. On testing for range of motion, there will be limitation of both internal and external rotation of the thigh (see Fig. 1). Most important, there is an absence of neurologic deficit.

Because in piriformis syndrome the effect on the sciatic nerve is largely chemical, negative findings by routine radiology including myelography, magnetic resonance imaging, or electromyography are of little help diagnostically.

The fact that lumbar disk syndrome and piriformis syndrome are frequently concurrent disorders should not be overlooked. Therefore, even with signs and symptoms of herniated disk, care should be taken to palpate the piriformis muscle for the possible detection of myofascial trigger points. Failure to detect and treat the piriformis lesion in such a case may result in persistence of the sciatica, even when the herniated disk is treated appropriately.

\section{Treatment}

We have found that a combination of osteopathic manipulative treatment with ethyl chloride spray and injection of 1 to $2 \mathrm{cc}$. of 1 percent lidocaine into the piriformis muscle is effective therapy for piriformis syndrome. Ethyl chloride or fluorimethene vapocoolants are sprayed on the buttocks over the piriformis muscle in the direction of its fibers. Physicians who prefer ethyl chloride want the greater volatility and more rapid cooling effect, while those who use fluorimethene do so because of its nonflammability.

Lidocaine is injected directly into palpable trigger points of the muscle using a 25-gauge, 1르-inch needle, which is thrust through the skin and subcutaneous tissue in one rapid motion. The most common trigger area is located about $3 \mathrm{~cm}$. caudal and lateral to the midpoint of the sacrum's lateral border. Because the piriformis muscle is attached to the greater trochanter of the femur, the entire length of the muscle should be palpated, and a second trigger point may be located closer to its trochanteric insertion.

The piriformis is stretched manually by applying a steady pressure perpendicular to the muscle's long axis and tangential to the surface of the but- 
tocks, until the muscle is felt to relax. This is performed with the patient prone and the physician on the side opposite the lesion. Reaching across the patient's buttocks, the physician places the butts of his/her hands against the inferior border of the piriformis muscle, with the palms lying over the body of the muscle. With arms extended, the physician leans his/her body weight against the piriformis muscle perpendicular to its long axis and tangential to the surface of the buttocks. It usually takes a few minutes before the muscle is felt to relax.

Mobilization of the lumbosacral spine is accomplished by muscle stretching and rotational manipulation. Assuming that the piriformis lesion is on the left side, the patient is placed in a right lateral recumbent position facing the physician. The physician places the fingers of his/her right hand on the left lumbar paravertebral muscles, and, using his/ her left hand, draws the patient's right arm forward, rotating the lumbar spine around the lumbosacral articulation. The patient's left leg is drawn toward the physician and gently supported as it swings over the edge of the table. The physician then palpates the left lumbar paravertebral musculature and stretches it perpendicular to the direction of its fibers. When sufficient tension has been reduced, the physician thrusts the left pelvis forward in the direction of the plane of the articulate facets, separating them and restoring the lumbosacral mobility. The thrust is carried out with the physician's right forearm on the patient's hip or thigh and his/her right hand palpating the joint being mobilized. If the physician's palpating fingers have been placed over the affected joint, he/she will be able to differentiate the achievement of motion in the appropriate articulation from random clicks in other areas. The technique varies according to the location and degree of lumbosacral rigidity and the size and configuration of the anatomic structures. The purpose of the mobilization is to ensure that the facets of the lumbar and lumbosacral vertebrae are mobilized.

The patient is instructed to follow with loosening exercises. The purpose of these exercises is to encourage the full range of joint motion and to prepare the body for more vigorous activities. They are not for increasing muscle bulk, but for the improvement of joint function and for the encouragement of healing. A list of patient instructions is presented in Table 1.

In light of the pathogenic mechanisms of sciatic neuritis, we attribute our therapy's effectiveness to the reduction of piriformis muscle spasm, the increase in joint motion, and the resultant reversal of the process that produced the sciatic neuritis. Mus-
TABLE 1. INSTRUCTIONS FOR PATIENTS WITH PIRIFORMIS SYNDROME.

(1) Gently roll from side to side in bed before arising in the morning. Turn on one side, slowly flex and extend the knees repeatedly; then, slowly turn to the other side and repeat the process. Do this for about 5 minutes.

(2) Hold on to a countertop or sink with both hands and do knee bends, 3 to 6 at a time, every few hours if possible.

(3) Do a loosening, sway exercise for a minute every few hours. The body should gently rotate back and forth by turning the hips (Fig. 3). The arms and shoulders should be totally relaxed and loose. The sway can be used when breaking up any period of immobilization and should always be performed before any sport or dance activity.

(4) Break up periods of reading, desk work, or watching television by getting up and walking around at 15 - or 20 minute intervals.

(5) Avoid staying in one position for extended periods of time. Break up long automobile trips by frequent stops.

(6) Take a warm bath (for at least 20 minutes) before going to bed at night. Bend your knees and settle into the water so that your shoulders are covered, and rest your head on a towel. Do not use applied heat to the skin, such as heating pads, hot water bottles, or wet cloths. It is the buoyancy effect of the water, rather than the heat, that allows the antigravity muscles to reduce their contraction.

(7) Do bicycle exercises in bed. While lying on the back, move the legs as if pedaling. After loosening a bit, if able, raise the hips with the hands and continue the movements.

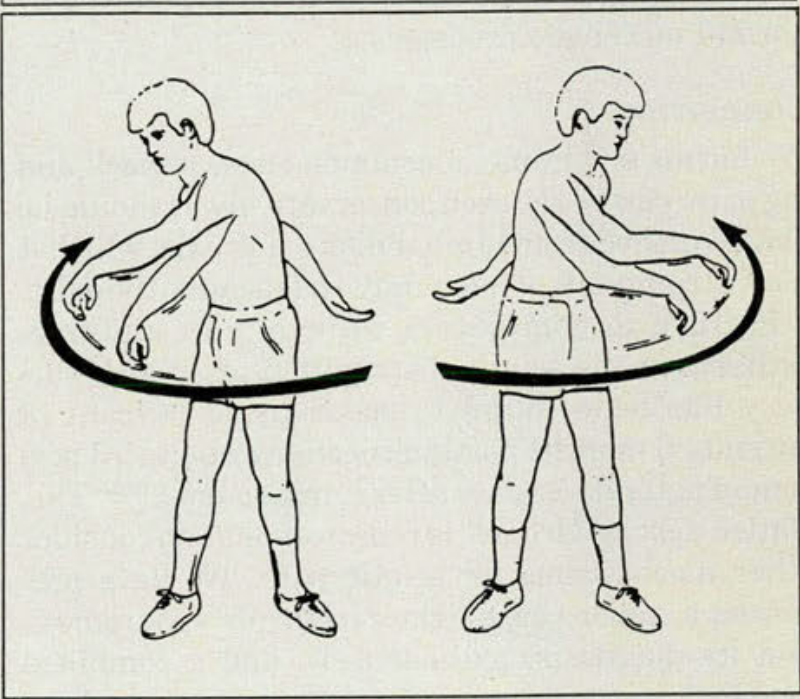

Fig. 3. In the gentle sway the motion is propelled by movements of the hips and legs. The trunk, upper body and arms loosely follow.

cle spasm directly results in continued tissue damage and inflammation of the muscle, and it restricts the blood flow and lymphatic drainage that is necessary to resolution of the myofibrositis.

Our combined therapy reduces muscle spasm in several ways. First, ethyl chloride spray and sustained pressure on the muscle may serve to disrupt 
the noxious afferent stimuli to the spinal cord that result in muscle spasm (the pain-spasm cycle). ${ }^{26}$ Second, lidocaine's anesthetic action on the muscle serves to block pain sensation in trigger points, which disrupts the pain-spasm cycle and allows more vigorous manipulative treatment of the muscle without pain. Third, stretching the muscle reduces muscle spasm, possibly by neural reflex inhibition mediated by Golgi tendon organs. ${ }^{27}$ Other beneficial effects of osteopathic manipulation are increased blood flow and reduction of fibrosis. ${ }^{3}$ Solheim, Siewers, and Paus, ${ }^{2}$ in performing surgical procedures on patients with piriformis syndrome, have found fibrous adhesions between the muscle and nerve. These may be reduced by osteopathic manipulative treatment, as described previously. Fourth, mobilization of the lumbosacral spine re-establishes the capacity of the vertebral bodies and facets to move freely in their physiologic range. ${ }^{4}$ This reduces irritation of vertebral column structures, which could result in muscle guarding. ${ }^{28}$

Keeping the patient ambulatory and in motion increases blood supply and lymphatic drainage, thus aiding resolution of the myofibrositis. Once the piriformis myofibrositis is eliminated, there is no further biochemical irritation of the sciatic nerve sheath, and the sciatic neuritis is resolved by normal metabolic processes.

\section{Conclusion}

Piriformis syndrome, a common cause of back and leg pain, can be relieved conservatively. It should be distinguished from lumbar disk syndrome, which it may accompany. It also may independently exist.

Failure to completely relieve pain and paresthesia in the sciatic distribution after disk surgery has been found to occur in 23 percent of patients 6 months postlaminectomy and in 73 percent of patients 2 years after laminectomy. ${ }^{10,15}$ This "failed disk syndrome" is reason enough to consider other mechanisms for sciatic pain. We have presented a major cause - the piriformis syndromeand its diagnosis, pathogenesis, and a combined modality in conservative treatment.

\footnotetext{
1. Pace, J.B., and Nagle, D.: Piriform syndrome. West J Med 124:435-9, Jun 76

2. Solheim, L.F., Siewers, P., and Paus, B.: The piriformis muscle syndrome. Sciatic nerve entrapment treated with section of the piriformis muscle. Acta Orthop Scand 52:73-5, Feb 81

3. Carron, H., and McLaughlin, R.E.: Management of low back pain. Ed

1. John Wright, PSG, Inc., Boston, 1982, pp. 36, 55-56

4. Steiner, C.: The ambulatory treatment of the disk syndrome. JAOA 77:290-7, Dec 77

5. Kelly, D.E., ed.: Bailey's Textbook of microscopic anatomy. Ed. 18 Williams and Wilkins, Baltimore, 1984, pp. 352-3, 374-6
}

6. Kristensson, K., and Olsson, Y.: The perineurium as a diffusion barrier to protein tracers. Acta Neuropathol 17:127-8, 1971

7. Lundborg, G.: Structure and function of the intraneural microvessels as related to trauma, edema formation, and nerve function. J Bone Joint Surg 57A:938-48, Oct 75

8. Olsson, Y., and Kristensson, K.: The perineurium as a diffusion barrier to protein tracers following trauma to nerves. Acta Neuropathol 23:105-11, 30 Jan 73

9. Murphy, R.W.: Nerve roots and spinal nerves in degenerative disk disease. Clin Orthop 129:46-60, Nov-Dec 77

10. Hromada, J.: On the nerve supply of the connective tissue of some peripheral nervous system components. Acta Anat 55:343-51, 1963

11. Lynn, B.: Cutaneous hyperalgesia. Br Med Bull 33:103-8, May 77

12. Fields, H.L., Meyer, G.A., and Partridge, L.D., Jr.: Convergence of visceral and somatic input onto spinal neurons. Exp Neurol 26:36-52, Jan 70

13. Jackson, C.M., ed.: Morris' Human anatomy. A complete systematic treatise by English and American authors. Ed. 5. P. Blakiston's Son and Company, Phildelphia, 1914, pp. 461, 1009

14. NacNab, I.: Pathogenesis of symptoms in discogenic low back pain. In American Academy of Orthopedic Surgeons symposium on the spine. C.V. Mosby Company, St. Louis, 1969, pp. 97-110

15. Spangfort, E.V.: The lumbar disc herniation. Acta Orthop Scand 142, 1972

16. Parke, W.W., and Watanabe, R.: The intrinsic vasculature of the lumbosacral spinal nerve roots. A computer-aided analysis of 2,504 operations. Spine 10:508-15, Jul-Aug 85

17. Rydevik, B., Brown, M.D., and Lundborg, G.: Pathoanatomy and pathophysiology of nerve root compression. Spine 9:7-15, Jan-Feb 84

18. Pleasure, D.E.: Nerve root compression. Effects on neural chemistry and metabolism. In The research status of spinal manipulative therapy (NINCDS monograph No. 15), edited by M. Goldstein. Department of Health, Education and Welfare, Bethesda, Maryland, 1975, pp. 197-202 19. Robbins, S.L., Cortran, R.S., and Kumar, V.: Pathologic basis of disease. Ed. 3. W.B. Saunders Co., Philadelphia, 1984, pp. 52-56

20. Fowler, T.J., Danta, G., and Gilliatt, R.W.: Recovery of nerve conduction after a pneumatic tourniquet. Observations on the hind-limb of the baboon. Neurol Neurosur Psychiatry 35:638-47, Oct 72

21. Awad, E.A.: Interstitial myofibrositis. Hypothesis of the mechanism. Arch Phys Med Rehab 54:449-53, Oct 73

22. Pace, J.B.: Commonly overlooked pain syndromes responsive to simple therapy. Postgrad Med 58:107-13, Oct 75

23. Christensen, L.V., and Moesmann, G.F.: Om den funktionsbetingede myoses aetiologi, patofysiologi og patoanatomi. Tandiaegeabladet 71:230-7, Mar 67

24. Flower, R.: Steroidal anti-inflammatory drugs as inhibitions of phospholipase $\mathbf{A}_{2}$. In Advances in prostaglandin and thromboxane research, edited by C. Galli, Raven Press, New York, 1978, vol. 3, pp. 105-12

25. Olsson, Y.: Studies on vascular permeability in peripheral nerves. Acta Physiol Scand 63S:1-22, 1966

26. Travell, J., and Rinzler, S.H.: The myofascial genesis of pain. Postgrad Med 11:425-34, May 52

27. Korr, I.M.: Proprioceptors and somatic dysfunction. JAOA 74:638-50, Mar 75

28. Bogduk, N.: The innervation of the lumbar spine. Spine 8:286-93, Apr 83

Accepted for publication June 1986. Updating, as necessary, has been done by the authors.

Dr. Steiner is professor and chairman of the Department of Osteopathic Sciences, University of Medicine and Dentistry of New Jersey, School of Osteopathic Medicine, and adjunct professor of bioengineering at Rutgers University, New Brunswick, New Jersey. Mr. Staubs is a student at UMDNJ-SOM. Drs. Ganon and Buhlinger were students at UMDNJ-SOM when the paper was written. Dr. Ganon is now in private family practice in Littleton, Colorado. Dr. Buhlinger is now in private practice of internal medicine in Morristown, New Jersey.

Dr. Steiner, 467 Valley Street, Maplewood, New Jersey 07040. 
For added blood pressure control, a major office-based study shows*...

\section{In the elderly}

regardless of previous therapy

\begin{tabular}{l|rcc}
\hline PREVIOUS & \multicolumn{4}{c}{ Change in BPt } \\
\cline { 2 - 4 } ANTIHYPERTENSIVE THERAPY & $\mathrm{n}$ & Systolic & Diastolic \\
\hline Beta blocker (monotherapy) & 1,206 & -22.9 & -12.43 \\
\hline Diuretic (monotherapy) & 820 & -24.2 & -14.4 \\
\hline Free combination & & & \\
$\cdot 2$ drugs & 2,346 & -17.8 & -10.2 \\
- 4 drugs & 517 & -17.9 & -9.6 \\
\hline Fixed combination & 142 & -18.7 & -10.8 \\
\hline
\end{tabular}

-TENORETIC Evaluation Program, an open 28-day study of 26,892 hypertensive patients (data on file, Stuart Pharmaceuticals, Wilmington, Delaware): physicians entered those patients needing more control than provided by monotherapy.

TENORETIC is not indicated for the initial therapy, of hypertension.

tDecreases in blood pressure were statistically significant. 


\section{In the elderly \\ without added side effects}

Total number of older patients treated: 9,098.

1 No adverse reactions reported in $89.2 \%$.

- Patients reported feeling either better than or as good as before: $94.7 \%$.

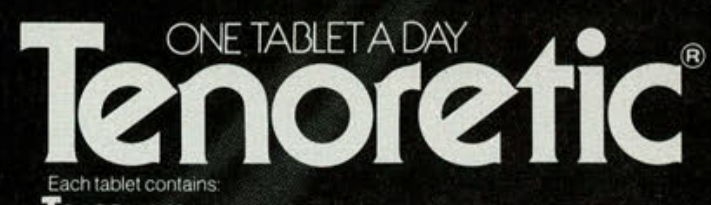

TENORMIN ${ }^{*}$ (atenolol) $50 \mathrm{mg}$ or $100 \mathrm{mg}$ and chlorthalidone $25 \mathrm{mg}$

For added control and convenience ...without added side effects. 
For added blood pressure control...

\section{In black males regardless of age*}

\begin{tabular}{lc|rr}
\hline \multirow{2}{*}{ Age } & & \multicolumn{2}{|c}{ Change in BPt } \\
\cline { 3 - 4 }$<40$ & $n$ & Systolic & Diastolic \\
\hline $40-60$ & 318 & -18.9 & -14.1 \\
\hline$>60$ & 828 & -20.5 & -13.9 \\
\hline
\end{tabular}

*TENORETIC Evaluation Program, an open 28-day study of 26,892 hypertensive patients (data on file, Stuart Pharmaceuticals, Wilmington, Delaware): physicians entered those patients needing more control than provided by monotherapy.

TENORETIC is not indicated for the initial therapy of hypertension.

tDecreases in blood pressure were statistically significant. 


\section{And in all patients regardless of age, race, sex*}

\begin{tabular}{lc|cc}
\hline & & \multicolumn{2}{|c}{ Change in BPt } \\
\cline { 3 - 4 } Type & $\mathrm{n}$ & Systolic & Diastolic \\
\hline Overall & 26,892 & -20.99 & -13.1 \\
\hline White & 19,185 & -20.9 & -12.9 \\
\hline Black & 3,701 & -21.2 & -13.5 \\
\hline Other & 1,147 & -22.3 & -13.8 \\
\hline Female & 12,540 & -21.6 & -13.1 \\
\hline Male & 11,844 & -20.3 & -13.1 \\
\hline
\end{tabular}

*TENORETIC Evaluation Program, an open 28-day study of 26,892 hypertensive patients (data on file, Stuart Pharmaceuticals, Wilmington, Delaware): physicians entered those patients needing more control than provided by monotherapy.

TENORETIC is not indicated for the initial therapy of hypertension.

tDecreases in blood pressure were statistically significant.

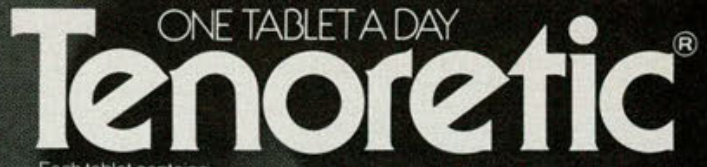

Each tablet contains.

TeNORMIN" (atenolol) $50 \mathrm{mg}$ or $100 \mathrm{mg}$ and chlorthalidone $25 \mathrm{mg}$

For added control and convenience ...without added side effects. 


\section{Tenoretic}

TorormiN

\section{Added control, added convenience ...without added side effects... regardless of age, race, or sex.}

\section{Please consult complete product information before prescribing.}

TENORETIC (atenolol and chlorthalidone) is for the treatment of hypertension. It combines the antihypertensive activity of two agents: a beta, selective (cardioselective) hydrophilic blocking agen (atenoloi, TENORMIN) and a monosulfonamyl diuretic (chlorthalidone)

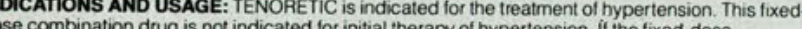
convenient represents the dose appropriate

CONTRAINDICATIONS: TENORETIC is contraindicated in patients with: sinus bradycardia, heart block greater than first degree, cardiogenic shock, overt cardiac failure (see WARNINGS), anuria, hypersensitivity to this product or to sulfonamide-derived drugs

function in congestive heart failure, and beta blockade carries the potential harard ciculatory depressing myocardial contractility and precipitating care severe failure. In hazard of furthe have congestive heart failure controlled by digitalis and diuretics. TENORETIC should be

administered cautiously. Both digitalis and atenolol slow AV conduction.

In Patients Without a History of Cardiac Failure: Continued depression of the myocardium with beta-blocking agents over a period of time can, in some cases, lead to cardiac failure. At the first sign or symptom of impending cardiac failure, patients receiving TENORETIC should be digitalized and/ be given additional diuretic therapy. Observe the patient closely If cardiac failure continues despite adequate digitalization and diuretic therapy. TENORETIC therapy should be withdrawn

Renal and Hepatic Disease and Electrolyte Disturbances: Since atenolol is excreted via the kidneys. TENORETIC should be used with caution in patients with impaired renal function.

In patients with renal disease, thiazides may precipitate azotemia. Since cumulative effects may develop in the presence of impaired renal function, if progressive renal impairment becomes evident, TENORETIC should be discontinued.

In patients with impaired hepatic function or progressive liver disease, minor alterations in fluid and electrolyte balance may precipitate hepatic coma. TENORETIC should be used with caution in these patients

Ischemic Heart Disease: Although not yet reported with atenolol following abrupt cessation of therapy with certain beta-blocking agents in patients with coronary artery disease exacerbations of angina pectoris and, in some cases, myocardial infarction have been reported. Therefore, such patients should be cautioned against interruption of therapy without the physician's advice. Even in the absence of overt angina pectoris, when discontinuation of TENORETIC is planned, the patient should be carefully observed and should be advised to limit physical activity to a minimum

Bronchospastic Diseases: PATIENTS WITH BRONCHOSPASTIC DISEASE SHOULD, IN GENERAL, NOT RECEIVE BETA BLOCKERS. Because of its relative beta -selectivity, however, TENORETIC may be used with caution in patients with bronchospastic disease who do not respond to, or cannot tolerate, other antihypertensive treatment. Since beta 1 -selectivity is not absolute, the lowest possible dose of TENORETIC should be used and a beta -stimulating ose should be considered in order to achieve lower peak blood levels.

Anesthesla and Major Surgery: As with all beta-receptor blocking drugs, it may be decided to withdraw TENORETIC before surgery. In this case, 48 hours should be allowed to elapse between the and anesthesia. If treatment is continued, care should be taken when using anesthetic agents because of the risk of further depression of the myocardium.

Beta blockers are competitive inhibitors of beta-receptor agonists and their effects on the heart can be reversed by administration of such agents; $e g$. dobutamine or isoproterenol with caution (see section on OVERDOSAGE). Manifestations of excessive v

ypotension) may be corrected with atropine (1-2 mg IV)

metabollc and Endocrine Effects: TENORETIC may be used with caution in diabetic patients Beta blockers may mask tachycardia occurring with hypoglycemia, but other manifestations such as hypoglycemia and, unlike nonselective beta blockers, does not delay recovery of blood glucose to ormal levels.

Insulin requirements in diabetic patients may be increased, decreased, or unchanged, latent diabetes mellitus may become manifest during chlorthalidone administration.

Beta-adrenergic blockade may mask certain clinical signs (eg, tachycardia) of hyperthyroidism. Abrupt withdrawal of beta blockade might precipitate a thyroid storm; therefore, patients suspected developing thyroto

Because calcium excretion is decreased by thiazides. TENORETIC should be discontinued before carrying out tests for parathyroid function. Pathologic changes in the parathyroid glands, with hypercalcemia and hypophosphatemia, have been observed in a few patients on prolonged thiazide therapy. however, the common complications of hyperparathyroidism such as renal lithiasis, bone esorption, and peptic ulceration have not been seen.

Hyperuricemia may occur or acute gout may be precipitated in certain patients receiving thiazide

PRECAUTIONS, General-Electrolyte and Fluid Balance Status: Periodic determination of serum electrolytes to detect possible electrolyte imbalance should be performed at appropriate intervals Patients should be observed for clinical signs of fluid or electrolyte imbalance; ie, hyponatremia hypochloremic alkalosis, and hypokalemia. Serum and urine electrolyte determinations are particularly important when the patient is vomiting excessively or receiving parenteral fluids. Warning signs or symptoms of fluid and electrolyte imbalance include dryness of the mouth, thirst, weakness.
lethargy, drowsiness, restlessness, muscle pains or cramps, muscular fatigue, hypotension, oliguria, lethargy, drowsiness, restlessness, muscle pains or cramps, muscular fatigue,
tachycardia, and gastrointestinal disturbances such as nausea and vomiting. Hypokalemia may develop, especially with brisk diuresis, when severe cirrhosis is present, or during
concomitant use of corticosteroids or ACTH.

Interference with adequate oral electrolyte intake will also contribute to hypokalemia. Hypokalemia
can sensitize or exaggerate the response of the heart to the toxic effects of digitalis (eg. increased ventricular irritability). Hypokalemia may be avoided or treated by use of potassium supplements or

oods with a high potassium conten

Any chloride deficit during thiazide therapy is generally mild and usually does not require specific treatment except under extraordinary circumstances (as in liver disease or renal disease). Dilutional hyponatremia may occur in edematous patients in hot weather; appropriate therapy is water restriction rather than administration of salt except in rare instances when the hyp
actual salt depletion, appropriate replacement is the therapy of choice.

actual salt depletion, appropriate replacement is the therapy of choice

Drug Interactions: TENORETIC may potentiate the action of other antihypertensive agents used
concomitantly. Patients treated with TENORETIC plus a catecholamine depletor (eg

concomitantly. Patients treated with TENORETIC plus a catecholamine depletor (eg. reserpine) should

be closely observed for evidence of hypoten
vertigo, syncope, or postural hypotension

Thiazides may decrease arterial responsiveness to norepinephrine. This diminution is not sufficie
vertigo, syncope, or postual hypotens

to preclude the therapeutic effectiveness of norepinephrine. Thiazides may increase the
responsiveness to tubocurarine.
Lithium generally should not be given with diuretics because they reduce its renal clearance and add a high risk of lithium toxicity. Read circulars for lithium preparations before use of such

ations with TENORETIC.

Should it be decided to discontinue therapy in patients receiving TENORETIC and clonidine concurrentine.

Other Precautions: In patients receiving thiazides, sensitivity reactions may occur with or without history of allergy or bronchial asthma. The possible exacerbation or activation of systemic lupus erythematosus has been reported. The antihypertensive effects of thiazides may be enhanced in the postsympathectomy patient. Carcinogenesis, Mutagenesis, Impairment of Fertillty: Two long-term (maximum dosing duration
of 18 or 24 months) rat studies and one long-term (maximum dosing duration of 18 months) mouse study with atenolol, each employing dose levels as high as $300 \mathrm{mg} / \mathrm{kg} /$ day or 150 times the maximum recommended human dose, did not indicate a carcinogenic potential in rodents.

Atenolol was negative in the mouse dominant lethal test, the Chinese hamster in vivo cytogenetic test and the Salmonella typhimurium back mutation test (Ames test), with or without metabolic

activation

Fertility of male or female rats (evaluated at dose levels as high as $200 \mathrm{mg} / \mathrm{kg} /$ day or 100 times the maximum recommended human dose) was unaffected by atenolol administration.

Use in Pregnancy: Pregnancy Category C. TENORETIC (atenolol and chlorthalidone) was studied for teratogenic potential in the rat and rabbit. Doses of 10,100 and $300 \mathrm{mg} / \mathrm{kg} /$ day were administered orally to pregnant rats, with no teratologic effects observed. Two studies were conducted in rabbits. In the first study, pregnant rabbits were dosed with 10,100 or $200 \mathrm{mg} / \mathrm{kg} /$ day. No teratologic changes were noted; embryonic resorptions were observed at all dose levels (ranging from approximately 5 times to 100 times the maximum recommended human dose). In a second rabbit study. dosages were 5,10 and $25 \mathrm{mg} / \mathrm{kg} /$ day. No teratogenic or embryotoxic effects were demonstrated. It is concluded that the no-effect level for embryonic resorptions is $25 \mathrm{mg} / \mathrm{kg} /$ day (approximately 12.5 times the maximum recommended human dose) or greater. TENORETIC

Atenoloj-Atenolol has been shown to produce a dose-related increase in embryo/fetal resorptions in rats at doses equal to or greater than $50 \mathrm{mg} / \mathrm{kg}$ or 25 or more times the maximum recommended human dose. Although similar effects were not seen in rabbits, the compound was not evaluated in rabbits at doses above $25 \mathrm{mg} / \mathrm{kg}$ or 12.5 times the maximum recommended human dose. There are no adequate and well-controlled studies in pregnant women.

chlorthalidone and related drugs in the placental barrier and appear in cord blood. The use of be weighed against possible Thesytopenia, and posible hazards to the fetus. These hazards include fetal or neonatal jaundice,

Nursing Mothers: It is not established to what extent this drug is occurred in the adult.

most drugs are excreted in human milk, nursing should not be undertaken by mothers receiving

Pediatric Use: Safety and effectiveness in children have not been established

ADVERSE REACTIONS: TENORETIC is usually well tolerated in properly selected patients. Most adverse effects have been mild and transient. The adverse effects

essentially the same as those seen with the individual components

Atenolol: The frequency estimates that follow derive from controlled studies in which adverse reactions were either volunteered by the patient (US studies) or elicited, eg. by checklist (foreign studies). The reported frequency of elicited adverse effects was higher for both atenolol and placebotreated patients than when these reactions were volunteered. Where frequency of adverse effects for atenolol and placebo is similar, causal relationship to atenolol is uncertain.

The data present these estimates in terms of percentages: first from the US studies (volunteered side effects) and then from both US and foreign studies (volunteered and elicited side effects):
US STUDIES (\% ATENOLOL-\% PLACEBO):

CARDIOVASCULAR: bradycardia (3\%-0\%), cold extremities (0\%-0.5\%), postural hypotension (2\%-1\%), leg pain $(0 \%-0.5 \%$

CENTRAL NERVOUS SYSTEM/NEUROMUSCULAR: dizziness ( $4 \%-1 \%)$, vertigo $(2 \%-0.5 \%$ ). lightheadedness $(1 \%-0 \%)$, tiredness $(0.6 \%-0.5 \%)$, fatigue $(3 \%-1 \%)$, lethargy $(1 \%-0 \%)$, drowsiness
$(0.6 \%-0 \%)$, depression $(0.6 \%-0.5 \%)$, dreaming $(0 \%-0 \%)$ $(0.6 \%-0 \%)$, depression $(0.6 \%-0.5 \%)$, dreaming $(0 \%-0 \%)$
GASTROINTESTINAL diarriea $(2 \%-0 \%)$, nausea $(4 \%$ )

RESPIRATORY (See WARNINGS): wheeziness $(0 \%-0 \%)$, dyspnea $(0.6 \%-1 \%)$

TOTALS US AND FOREIGN STUDIES:

CARDIOVASCULAR: bradycardia (3\%-0\%), cold extremities (12\%-5\%), postural hypotension CENT), leg pain $(3 \%-1 \%)$

CENTRAL NERVOUS SYSTEM/NEUROMUSCULAR: dizziness (13\%-6\%), vertigo $(2 \%-0.2 \%)$, light headedness $(3 \%-0.7 \%)$, tiredness $(26 \%-13 \%)$, fatigue $(6 \%-5 \%)$, lethargy $(3 \%-0.7 \%)$, drowsiness $2 \%-0.5 \%)$, depression $(12 \%-9 \%)$, dreaming $(3 \%-1 \%)$
GASTROINTESTINAL diarmea $(3 \%-2 \%)$ nausea $(3 \%-1)$

GASTROINTESTINAL: diarthea $(3 \%-2 \%)$, nausea $(3 \%-1 \%)$

RESPIRATORY (see WARNINGS): wheeziness $(3 \%-3 \%)$, dyspnea ( $6 \%-4 \%$ )

MISCELLANEOUS: There have been reports of skin rashes and/or dry eyes associated with the use of beta-adrenergic blocking drugs. The reported incidence is small and, in most cases, the symptoms have cleared when treatment was withdrawn. Discontinuance of the drug should be considered if any
such reaction is not otherwise explicable. Patients should be closely monitored following cessation of such reactio

Chlorthalidone: Cardiovascular, orthostatic hypotension; Gastrointestinal: anorexia gastric irritation, vomiting, cramping, constipation, jaundice (intrahepatic cholestatic jaundice), pancreatitis; CNS: vertigo, paresthesias, xanthopsia; Hematologic: leukopenia, agranulocytosis, thrombocytopenia aplastic anemia: Hypersensitivity: purpura, photosensitivity, rash, urticaria, necrotizing angiitis
(vasculitis, cutaneous vasculitis), Lyell's syndrome (toxic epidermal necrolysis): Miscellaneous hyperglycemia, glycosuria, hyperuricemia, muscle spasm, weakness, restlessness. Clinical trials of ENORETIC conducted in the United States (89 patients treated with TENORETIC) revealed no new or

Potential Adverse Effects: In addition, a variety of adverse effects not observed in clinical trials with atenolol but reported with other beta-adrenergic blocking agents, should be considered potentia adverse effects of atenolol. Nervous System: reversible mental depression progressing to catatonia:
hallucinations; an acute reversible syndrome characterized by disorientation for time and place. short-lerm memory loss, emotional lability, slightly clouded sensorium, decreased performance on neuropsychometrics; Cardiovascular: intensification of AV block (see CONTRAINDICATIONS) Gastrointestinal; mesenteric arterial thrombosis, ischemic colitis, Hematologic: agranulocytosis, nonthrombocytopenic purpura, thrombocytopenic purpura: Allergic: erythematous rash, feve combined with aching and sore throat, laryngospasm and respiratory distress; Miscellaneous There have been

there have been reports of a syndrome comprising psoriasitorm skin rash, conjunctivitis sicca otitis, and sclerosing serositis attributed to the beta-adrenergic receptor blocking agent, practolol. Clinical Laboratory Test Findings: Clinically important changes in (atenolo)

Clinical Laboratory Test Findings: Clinically important changes in standard laboratory parameters were rarely associated with the administration of TENORETIC. The changes in laboratory parameters were not progressive and usually were not associated with clinical manifestations. The most common changes were increases in uric acid and decreases in serum potassium DOSAGE AND ADMINISTRATION: Initial dose should be one TENORETIC 50 tablet once a day. II optimal response is not achieved, the dosage should be increased to one TENORETIC 100 table once a day. Package insert shou
impairment of renal function.

impairment of renal function

(a) (white, round, biconvex, uncoated tablets with TENORETIC 50 on one side and Stuart 115 on the
other side) are supplied in bottles of 100 tablets. TENORETIC 100 Tablets (atenolol $100 \mathrm{mg}$ and other side) are supplied in bottles of 100 tablets. TENORETIC 100 Tablets (atenolol $100 \mathrm{mg}$ and
chlorthalidone $25 \mathrm{mg}$ ). NDC $0038-0117$ (white, round, biconvex, uncoated tablets with TENORETIC 100 on one side and Stuart 117 on the other side) are supplied in bottles of 100 tablets.

Protect from heat, light, and moisture. Dispense in well-closed, light-resistant containe

Inactive ingredients: magnesium stearate, microcrystalline cellulose, povidone, sodium starch

\section{STUART PHARMACEUTICALS}

Division of ICl Americas Inc

Wilmington, DE 19897 